\title{
Performance Analysis of Photovoltaic System using Proposed Assessment Method: An Inquiry on Output Energy Analysis Depending on Distance
}

\author{
Shin Min-Su* · Kwon Oh-Hyun* • Lee Sang-Hyuk* • Lee Kyung-Soo**† \\ *Master Course Student, Department of Energy \& Electrical Engineering, Korea Polytechnic University \\ ${ }^{* *}$ Associate Professor, Department of Energy \& Electrical Engineering, Korea Polytechnic University \\ ${ }^{\dagger}$ Corresponding author: kyungsoolee@kpu.ac.kr
}

\begin{abstract}
The losses in grid-connected photovoltaic (PV) power generation systems were calculated using the monitoring data that were collected in 2018-2019 from the path between the input and output energy. Thus, the various loss factors were identified. The performances of seven PV power plants in a specific area of Korea were evaluated by developing a quantitative performance evaluation model based on the loss factors. The meteorological environment data were considered vital for the accurate quantification of the input energy in this model. We performed quantitative analyses of the performance deviations and the errors, based on the distances between the weather-monitoring locations and the PV power plants. The proposed analytical method employed two sets of meteorological data that were obtained from the monitoring stations at different locations. Furthermore, one set of interpolated data was employed to quantify the deviations between the expected power and the actual power. The expected power was estimated using the proposed assessment method, while the actual power was measured at the seven PV power plants that were 1.2-17.1 [km] away from the location of the meteorological data measurement. When the distance between the input energy and the plant was minimum (1.2 $[\mathrm{km}]$ ), the root mean square error (RMSE) and the mean absolute error (MAE) of the output energy were $0.0633\left[\mathrm{kWh} / \mathrm{kW}_{\mathrm{P}} / \mathrm{h}\right]$ and $0.0396\left[\mathrm{kWh} / \mathrm{kW}_{\mathrm{P}} / \mathrm{h}\right]$, respectively. When the distance between the input energy and the plant was maximum $(17.1[\mathrm{~km}])$, the RMSE and MAE of the output energy were $0.1202\left[\mathrm{kWh} / \mathrm{kW}_{\mathrm{P}} / \mathrm{h}\right]$ and $0.0854[\mathrm{kWh} / \mathrm{kW} / \mathrm{h}]$, respectively. Therefore, the error increased with the increase in the distance between the input energy and the PV power plants. It was interesting to note that the errors remained high for two of the seven sites, irrespective of the distance from the input energy. These sites were investigated via site inspections; thus, the errors were ascribed to factors such as module shading and incorrect system installation.
\end{abstract}

Keywords: Photovoltaic system, Performance assessment, Regression equation, PVSYST, Field test

\section{Introduction}

PV systems are attracting attention as efficient alternative energy sources to fossil

This is an Open-Access article distributed under the terms of the Creative Commons Attribution NonCommercial License which permits unrestricted non-commercial use, distribution, and reproduction in any medium, provided the original work is properly cited. fuls owing to their high level of applicability compared to other renewable energy sources, and they are expected to become ubiquitous in the near future ${ }^{1,2)}$. Therefore, the 
performance and quality of existing and future PV power generation systems are important. To realise sustained production of appropriate amounts of PV power over periods longer than 30 years while considering environmental factors such as installation, recycling, and disposal, a method for PV performance evaluation is required to maximize the conversion of solar energy into system output at all times ${ }^{3)}$. However, systematic operation management guidelines related to the installation environment, method, construction system, optimal design, and post-installation maintenance of PV systems in the field are lacking ${ }^{4)}$. In addition, compared to other renewable energy sources, PV power generation systems are known to require no maintenance, but in practice, their output is lower than the design value owing to various reasons such as shading, contamination, and crack failure ${ }^{5)}$. Therefore, it is essential to devise methods to quantify the performance and reduce the losses of PV systems. Recently, a $10\left[\mathrm{MW}_{\mathrm{P}}\right] \mathrm{PV}$ power plant commissioned in India was designed considering environmental conditions such that the angle of inclination of individual solar panels changes according to the season, and the performance ratio of this plant was calculated considering several types of lossesq. Moreover, the losses of a $75\left[\mathrm{MW}_{\mathrm{P}}\right]$ PV power plant commissioned in South Africa were analyzed, and the simulation results obtained for this plant were compared with the corresponding measured values ${ }^{7}$. However, these studies presented the analysis results of a single large-scale PV power plant, and performance evaluation based on a comparison according to plant distance from the location of measurement of meteorological input value to several PV sites was not implemented.

\section{Methodology}

In this study, errors in the performance assessment of PV systems according to distance were analyzed using meteorological dataset corresponding to Case $1 \sim 3$. Meteorological data on irradiance and air temperature obtained from the Siheung and Suwon areas were used in this study. The PV plants were located in the Ansan area. Moreover, average hourly meteorological data and power generation data were used. Errors in performance assessment were analyzed using indicators such as RMSE and MAE after, and sites with relatively large errors were identified through on-site inspections.

\subsection{Composition of meteorological data and PV plants' energy output by monitoring system}

We used specialized equipment to measure the amount of light energy and temperature for determining the amount of input energy before assessing PV system performance. The data measured using the equipment were divided into global horizontal irradiance and atmospheric temperature, and the meteorological sensors were located in Siheung and Suwon at a straight distance of approximately $23[\mathrm{~km}]$ from each other. Table 1 lists the 
specifications of the pyranometer and thermometer installed in the Siheung and Suwon areas. Irradiance and atmospheric temperature data were collected over a period of two years (January 2018 to December 2019), and irradiance values of $100\left[\mathrm{~W} / \mathrm{m}^{2}\right]$ or lower were excluded from the study to improve the validity of our results ${ }^{8)}$.

Table 1 Specifications of meteorological equipment

\begin{tabular}{|c|c|c|c|c|c|}
\hline \multirow{2}{*}{ Category } & \multicolumn{2}{|c|}{ Pyranometer } & \multirow{2}{*}{ Category } & \multicolumn{2}{|c|}{ Thermometer } \\
\hline & Siheung & Suwon & & Siheung & Suwon \\
\hline \multirow[t]{2}{*}{$\begin{array}{c}\text { Image } \\
\text { (company / model) }\end{array}$} & & & $\begin{array}{c}\text { Image } \\
\text { (company / model) }\end{array}$ & & \\
\hline & $\begin{array}{l}\text { Delta OHIM / LP } \\
\text { PYRA } 02\end{array}$ & EKO / MS-802 & & $\begin{array}{l}\text { Delta OHM / } \\
\text { HD9008TR }\end{array}$ & $\begin{array}{l}\text { JINYANG / } \\
\text { JY-100829 }\end{array}$ \\
\hline Sensitivity & $\begin{array}{l}10[\mu \mathrm{V}] \\
\left(\mathrm{W} / \mathrm{m}^{2}\right)\end{array}$ & $\begin{array}{c}7[\mu \mathrm{V}] \\
\left(\mathrm{W} / \mathrm{m}^{2}\right)\end{array}$ & Resolution & $\begin{array}{l}-40\left[{ }^{\circ} \mathrm{C}\right]=4[\mathrm{~mA}] \\
80\left[{ }^{\circ} \mathrm{C}\right]=20[\mathrm{~mA}]\end{array}$ & $0.1\left[{ }^{\circ} \mathrm{C}\right]$ \\
\hline Working temperature & \multicolumn{2}{|c|}{$-40 \sim 80\left[{ }^{\circ} \mathrm{C}\right]$} & Accuracy & $\pm 0.15\left[{ }^{\circ} \mathrm{C}\right]$ & $\pm 0.3\left[{ }^{\circ} \mathrm{C}\right]$ \\
\hline $\begin{array}{l}\text { Measurement } \\
\text { range }\end{array}$ & $\begin{array}{c}0 \sim 2000 \\
{\left[\mathrm{~W} / \mathrm{m}^{2}\right]}\end{array}$ & $\begin{array}{c}0 \sim 4000 \\
{\left[\mathrm{~W} / \mathrm{m}^{2}\right]}\end{array}$ & $\begin{array}{l}\text { Measurement } \\
\text { range }\end{array}$ & $-40 \sim 80\left[{ }^{\circ} \mathrm{C}\right]$ & $-40 \sim 60\left[{ }^{\circ} \mathrm{C}\right]$ \\
\hline Response time & $<28[\mathrm{~s}]$ & $<5[\mathrm{~s}]$ & Response time & $60[s]$ & $45[\mathrm{~s}]$ \\
\hline
\end{tabular}

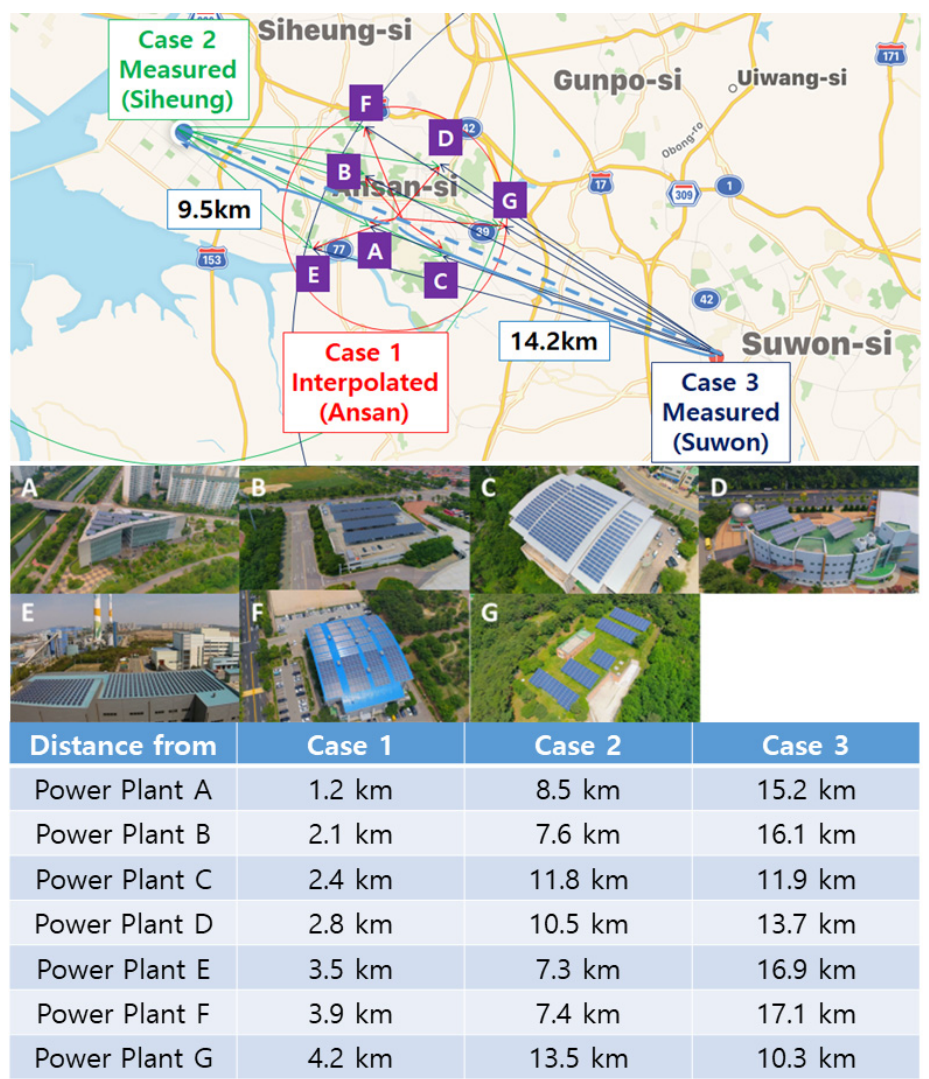

Fig. 1 Distances of PV plants from location of input energy, and panorama of PV plants 
Table 2 System configuration for each power plant

\begin{tabular}{|c|c|c|c|c|c|c|c|}
\hline Sites & $\begin{array}{c}\text { Completion } \\
\text { date }\end{array}$ & Module & $\begin{array}{c}\text { Array capacity } \\
{\left[\mathrm{kW}_{\mathrm{P}}\right]}\end{array}$ & $\begin{array}{c}\text { Tilted angle } \\
{\left[{ }^{\circ}\right]} \\
\end{array}$ & Azim & $\begin{array}{l}\text { th angle } \\
\text { o] }\end{array}$ & Inverter \\
\hline PV plant A & 2013.05. 21 & $\begin{array}{l}\text { LG250S1C } \\
\left(250\left[\mathrm{~W}_{\mathrm{P}}\right]\right)\end{array}$ & 49.8 & 30 & 0 & (S) & $\begin{array}{c}\text { Powador } 39.0 \\
\text { TL3 }\end{array}$ \\
\hline PV plant B & 2015. 06. 30 & $\begin{array}{l}\text { LG280S1W-B3 } \\
\left(280\left[\mathrm{~W}_{\mathrm{P}}\right]\right)\end{array}$ & 299.9 & 20 & 4 & $(\mathrm{SW})$ & XP100-HV \\
\hline PV plant $\mathrm{C}$ & 2017. 11. 14 & \multirow{2}{*}{$\begin{array}{l}\text { Q.PLUS L-G4.1 } 335 \\
\left(335\left[\mathrm{~W}_{\mathrm{P}}\right]\right)\end{array}$} & 99.8 & 3 & 2.5 & $(\mathrm{SW})$ & \multirow{5}{*}{$\begin{array}{c}\text { Sunny Tripower } \\
25000 \mathrm{TL}\end{array}$} \\
\hline PV plant D & 2017.11 .01 & & 50.3 & 25 & 0 & (S) & \\
\hline PV plant E & 2017.05 .25 & $\begin{array}{c}\text { HSL 72P6-PC-5-315 } \\
\left(315\left[\mathrm{~W}_{\mathrm{P}}\right]\right)\end{array}$ & 149.9 & 16 & -14 & (SE) & \\
\hline PV plant $F$ & 2017. 12.18 & $\begin{array}{c}\text { Q.PLUS L-G4.2 } 335 \\
\left(335\left[\mathrm{~W}_{\mathrm{P}}\right]\right)\end{array}$ & 199.3 & $\begin{array}{c}25 \text { (attached), } \\
6 \sim 20 \text { (rounded) }\end{array}$ & 4 & $(\mathrm{SW})$ & \\
\hline PV plant G & 2017.01 .23 & $\begin{array}{c}\text { HSL 72P6-PC-5-315 } \\
\left(315\left[\mathrm{~W}_{\mathrm{P}}\right]\right)\end{array}$ & 99.9 & 20 & -9 & (SE) & \\
\hline
\end{tabular}

For performance assessment of PV systems, on-site energy yields of each plant were collected using data loggers and data collection equipment over a period of two years. Seven power plants distributed at various distances from the source of input energy acquisition were analyzed in this study. Fig. 1 shows the locations and an overview of the fields in which power generation data were collected and the location relationship between the Siheung and Suwon areas, where meteorological data were collected. Table 2 lists the capacities and other details of each of the plants.

\subsection{Performance assessment method}

General pre-installation engineering guidelines such as feasibility analysis, design, operation and maintenance, and performance evaluation are lacking. Therefore, after the installation of a PV system, a performance evaluation model can be used to quantify the energy yield and failure probability of the system, as well as to optimize the system design and verify the reliability of system performance. A schematic diagram of the proposed PV performance evaluation checklist and procedures is shown in Fig. 2.

Each of the seven PV power plant sites was estimated and analyzed by implementing a virtual design and by means of site evaluation. The use of mutual information in virtual design and site evaluation analyses makes it possible to quantitatively evaluate PV systems through comparison and analysis of the simulation results obtained using the proposed PV performance evaluation model and the field measurement results, as well as to determine system failure, system performance trends, and system aging through regular performance evaluations. According to the performance evaluation procedure shown in Fig. 2, system configuration check, collection of monitoring data, settings of the performance evaluation model, simulation 


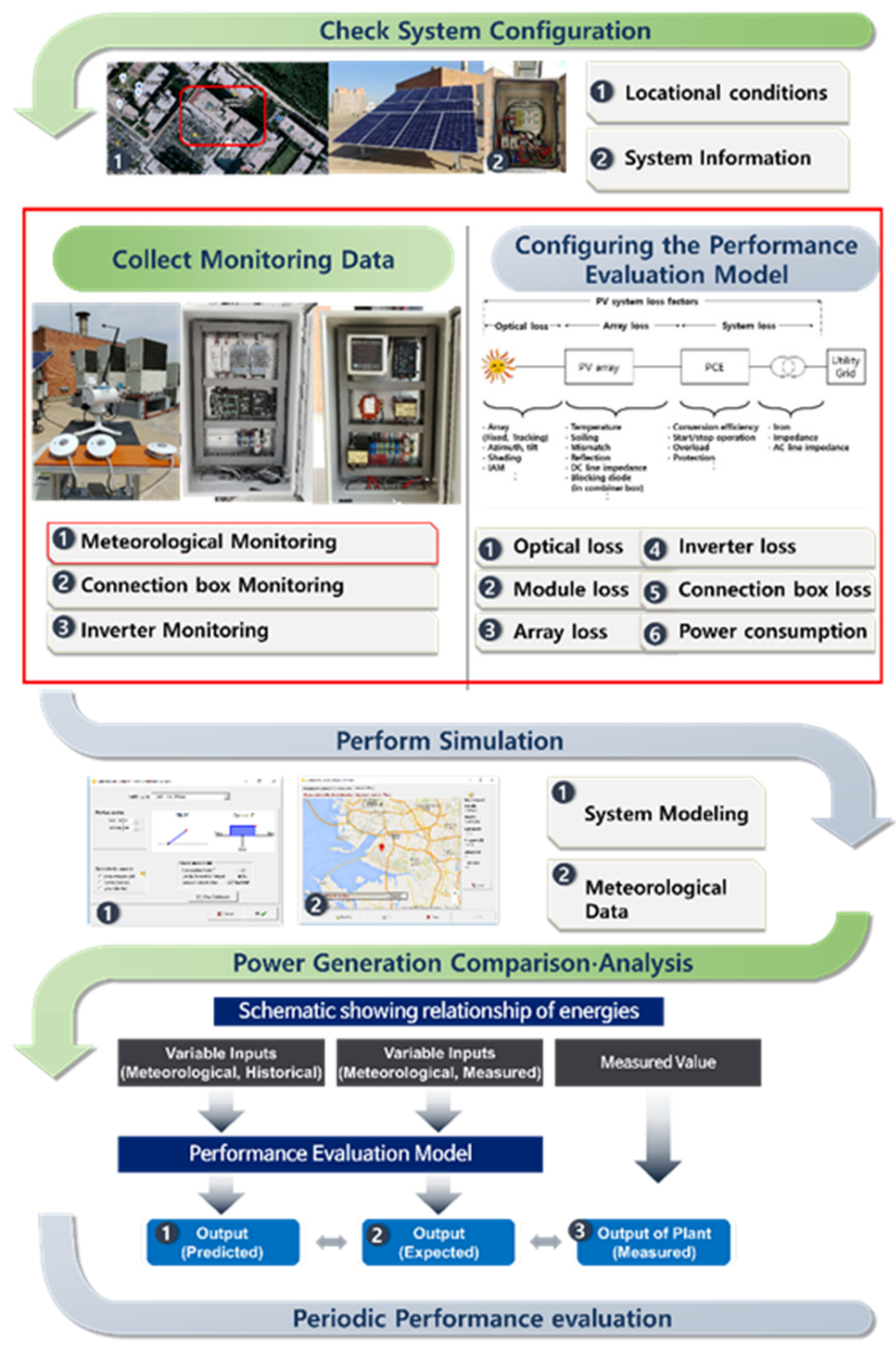

Fig. 2 Proposed performance assessment method ${ }^{5)}$

runs, comparison of power outputs, and periodic performance evaluation runs were executed. Meteorology data are essential for collecting monitoring data and accurately calculating the input energy. Because the input energy varies depending on the system installation structure and environmental conditions, PV power plant performance is affected by incident irradiance, ambient temperature, module temperature, wind direction, and wind speed. In PV performance evaluation, energy flow from the input to the output must be accurately reflected in the performance evaluation model.

Therefore, in this study, we created a virtual design and performed field evaluations to develop a performance evaluation model. System performance was predicted using a simulation program that took 
meteorology data measured in the past as the input. Thereafter, a virtual design was developed based on specific field surveys of actual PV systems and the details of each system component, including electrical drawings, inverters, grids, monitoring systems, and loss factors. In this study, PVSYST, a widely used program for calculating PV energy yields and performing loss analysis, was used. PV system losses include optical losses, module and array losses, and power conditioning system (PCS) losses. On-site assessments were conducted to ensure that the PV power plants were able to provide a stable supply of electricity. Furthermore, routine inspections were performed, and measurement equipment were used to analyze system performance and monitor system failures. The performance ratio, performance index, and normalized energy yield, which are performance evaluation indicators, were compared and analyzed to validate the results. A simulation was implemented by feeding the meteorology monitoring data obtained at $\mathrm{K}$ university, those obtained at Suwon Meteorological Agency, and the interpolated data as input energy into PVSYST. Normalized energy yield was expressed as the total power generation divided by the standard test condition rating of the PV system. The accuracy of the calculated daily power of the PV systems was confirmed by analyzing the RMSE, MAE, and $\mathrm{R}^{2}$. RMSE is the absolute difference between two dataset, and it is a measure of the amount of error in the data. MAE is an indicator of the degree to which error accounts for the expected value. $\mathrm{R}^{2}$ represents the goodness-of-fit for the regression of two dataset ${ }^{9)}$.

$$
\begin{aligned}
& M A E=\frac{1}{n} \sum\left|x_{1, i}-x_{2, i}\right| \\
& R M S E=\sqrt{\frac{\sum_{i=1}^{n}\left(x_{1, i}-x_{2, i}\right)^{2}}{n}} \\
& R^{2}=\frac{Q-Q_{e}}{Q}
\end{aligned}
$$

Here, $\mathrm{x}_{1, \mathrm{i}}$ is the model-predicted value, $\mathrm{x}_{2, \mathrm{i}}$ is the measured value, $\mathrm{Q}$ is the total sum of squares, and $\mathrm{Q}_{\mathrm{e}}$ is the explained sum of squares.

\section{Quantitative analysis of PV system performance by distance}

By using the performance evaluation model developed in this study, we evaluated the performance of seven PV power plant sites in the Ansan area. The criteria for categorising a plant under either Case 1, Case 
2, or Case 3 were that the plant should be located within the maximum diameters of approximately 4.2 [km], $13.5[\mathrm{~km}]$, and $17.1[\mathrm{~km}]$ from the site of input energy. For Case 1, the input energy was calculated through linear interpolation of the input energies of Cases 2 and 3 by using Equation (4).

$$
p(x)=\frac{y_{i}\left(x-x_{i+1}\right)-y_{i+1}\left(x-x_{i}\right)}{x_{i}-x_{i+1}}
$$

Fig. 3 shows the measured and modeled normalized energy yields in units of hourly mean as functions of the input energy. The graph confirms that as the distance between the meteorological sensor and the plant increases (Case 1 to 3 ), the error range of the modeled value widens.

Moreover, Table 3 lists the RMSE, MAE, and $\mathrm{R}^{2}$ of the error between the measured and expected values as functions of different distances from the source of input energy. In the cases of power plants A, B, C, D, and $\mathrm{G}$, as the distance from the location of input energy acquisition increased, the RMSE and MAE increased, and as $\mathrm{R}^{2}$ decreased, the error between the measured and expected values increased. In the case of power plant $\mathrm{C}$, since it is $11.8[\mathrm{~km}]$ and $11.9[\mathrm{~km}]$ away from the input energy, it is judged as an error due to a slight difference in distance. In the cases of power plants $\mathrm{E}$ and $\mathrm{F}$, regardless of the distance, the error between the measured value and the expected value changed, and the sites themselves hindered power generation performance. The smallest error between the measured and expected values was obtained for power plant A for the input energy of Case 1: RMSE was $0.0633\left[\mathrm{kWh} / \mathrm{kW}_{\mathrm{P}} / \mathrm{h}\right]$, MAE was $0.0396\left[\mathrm{kWh} / \mathrm{kW}_{\mathrm{P}} / \mathrm{h}\right]$, and $\mathrm{R}^{2}$ was 0.9386. By contrast, the largest error between the measured and expected values was obtained for power plant F for the input energies of Cases 1 and 2: RMSE values were $0.1278[\mathrm{kWh} / \mathrm{kW} / \mathrm{h}]$ and $0.1202\left[\mathrm{kWh} / \mathrm{kW}_{\mathrm{P}} / \mathrm{h}\right]$, MAE values were $0.0878\left[\mathrm{kWh} / \mathrm{kW}_{\mathrm{P}} / \mathrm{h}\right]$ and $0.0854\left[\mathrm{kWh} / \mathrm{kW}_{\mathrm{P}} / \mathrm{h}\right]$, and $\mathrm{R}^{2}$ values were 0.8011 and 0.7686 , respectively. For power plant $\mathrm{F}$, the expected value was approximately $15 \%$ higher than the measured value, which implied the existence of factors that caused more losses than those in the case of other plants, regardless of the distance from the input energy source.

Fig. 4 shows the trend of the error as a function of the distance between the location of input energy acquisition and each power plant. The error trend except $\mathrm{C}, \mathrm{E}$, and $\mathrm{F}$ as mentioned in Table 3 quantitatively confirms that the error increases as the distance between a plant and the location of input energy acquisition increases. 

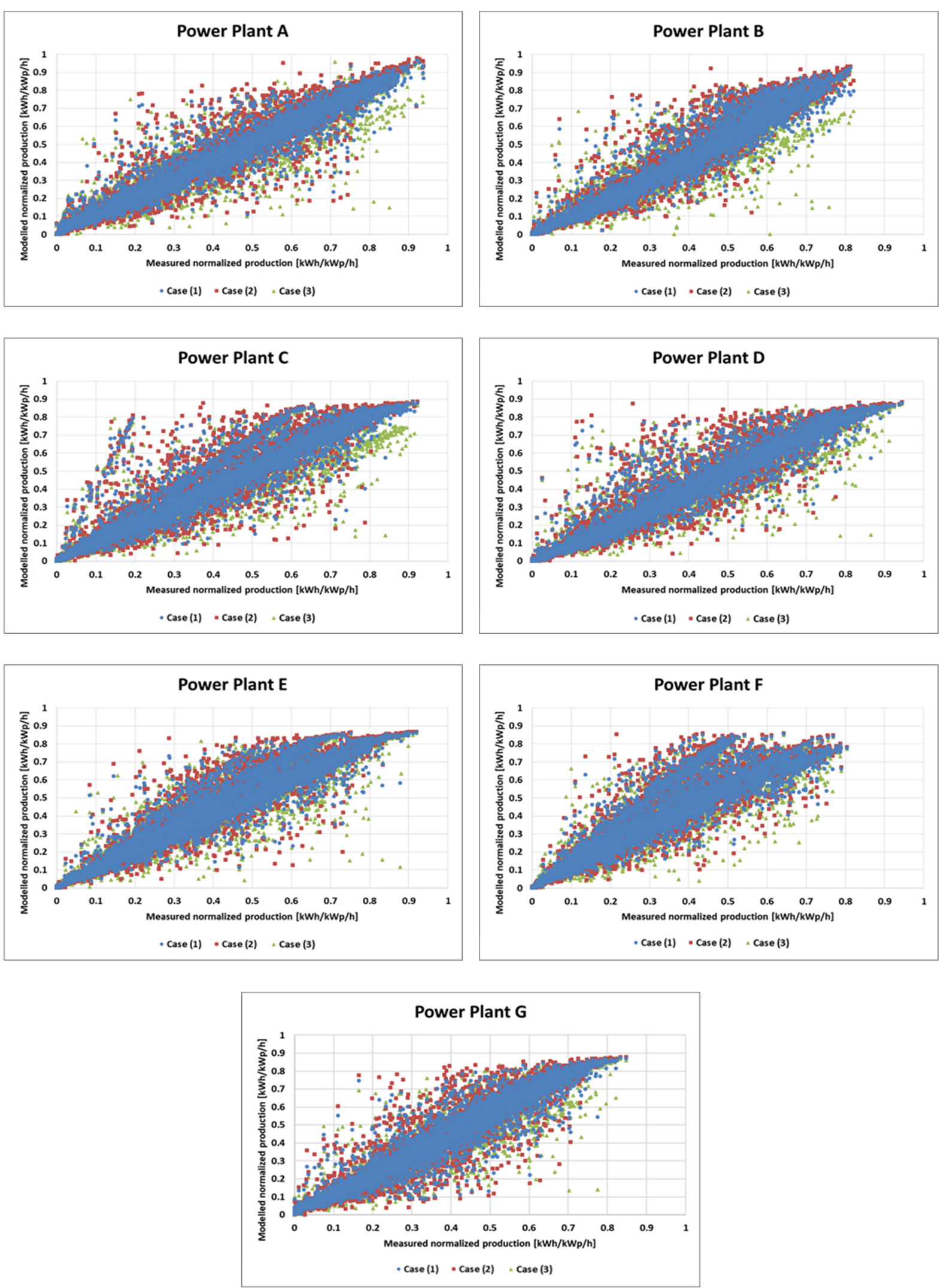

Fig. 3 Measured and modeled normalized production as functions of input energy (hourly data) 
Table 3 Analysis of prediction accuracy for the seven power plants (RMSE: [kWh/kWp/h], MAE: [kWh/kWp/h])

\begin{tabular}{|c|c|c|c|}
\hline \multicolumn{4}{|c|}{ Power plant A } \\
\hline Distance & RMSE & MAE & $\mathrm{R}^{2}$ \\
\hline $1.2[\mathrm{~km}]$ & 0.0633 & 0.0396 & 0.9386 \\
\hline $8.5[\mathrm{~km}]$ & 0.0776 & 0.0484 & 0.9167 \\
\hline $15.2[\mathrm{~km}]$ & 0.0824 & 0.0511 & 0.8912 \\
\hline \multicolumn{4}{|c|}{ Power plant B } \\
\hline Distance & RMSE & MAE & $\mathrm{R}^{2}$ \\
\hline $2.1[\mathrm{~km}]$ & 0.0755 & 0.0500 & 0.9282 \\
\hline $7.6[\mathrm{~km}]$ & 0.0873 & 0.0584 & 0.9148 \\
\hline $16.1[\mathrm{~km}]$ & 0.0892 & 0.0593 & 0.8688 \\
\hline \multicolumn{4}{|c|}{ Power plant $\mathrm{C}$} \\
\hline Distance & RMSE & MAE & $\mathrm{R}^{2}$ \\
\hline $2.4[\mathrm{~km}]$ & 0.0818 & 0.0474 & 0.8982 \\
\hline $11.8[\mathrm{~km}]$ & 0.0978 & 0.0583 & 0.8707 \\
\hline $11.9[\mathrm{~km}]$ & 0.0950 & 0.0577 & 0.8521 \\
\hline \multicolumn{4}{|c|}{ Power plant D } \\
\hline Distance & RMSE & MAE & $\mathrm{R}^{2}$ \\
\hline $2.8[\mathrm{~km}]$ & 0.0702 & 0.0414 & 0.9231 \\
\hline $10.5[\mathrm{~km}]$ & 0.0844 & 0.0498 & 0.8968 \\
\hline $13.7[\mathrm{~km}]$ & 0.0849 & 0.0498 & 0.8812 \\
\hline \multicolumn{4}{|c|}{ Power plant E } \\
\hline Distance & RMSE & MAE & $\mathrm{R}^{2}$ \\
\hline $3.5[\mathrm{~km}]$ & 0.0820 & 0.0552 & 0.8937 \\
\hline $7.3[\mathrm{~km}]$ & 0.0933 & 0.0627 & 0.8755 \\
\hline $16.9[\mathrm{~km}]$ & 0.0927 & 0.0615 & 0.8473 \\
\hline \multicolumn{4}{|c|}{ Power plant $\mathrm{F}$} \\
\hline Distance & RMSE & MAE & $\mathrm{R}^{2}$ \\
\hline $3.9[\mathrm{~km}]$ & 0.1169 & 0.0808 & 0.8164 \\
\hline $7.4[\mathrm{~km}]$ & 0.1278 & 0.0878 & 0.8011 \\
\hline $17.1[\mathrm{~km}]$ & 0.1202 & 0.0854 & 0.7686 \\
\hline \multicolumn{4}{|c|}{ Power plant G } \\
\hline Distance & RMSE & MAE & $\mathrm{R}^{2}$ \\
\hline $4.2[\mathrm{~km}]$ & 0.0848 & 0.0635 & 0.9147 \\
\hline $10.3[\mathrm{~km}]$ & 0.0880 & 0.0656 & 0.8838 \\
\hline $13.5[\mathrm{~km}]$ & 0.1017 & 0.0757 & 0.8819 \\
\hline
\end{tabular}
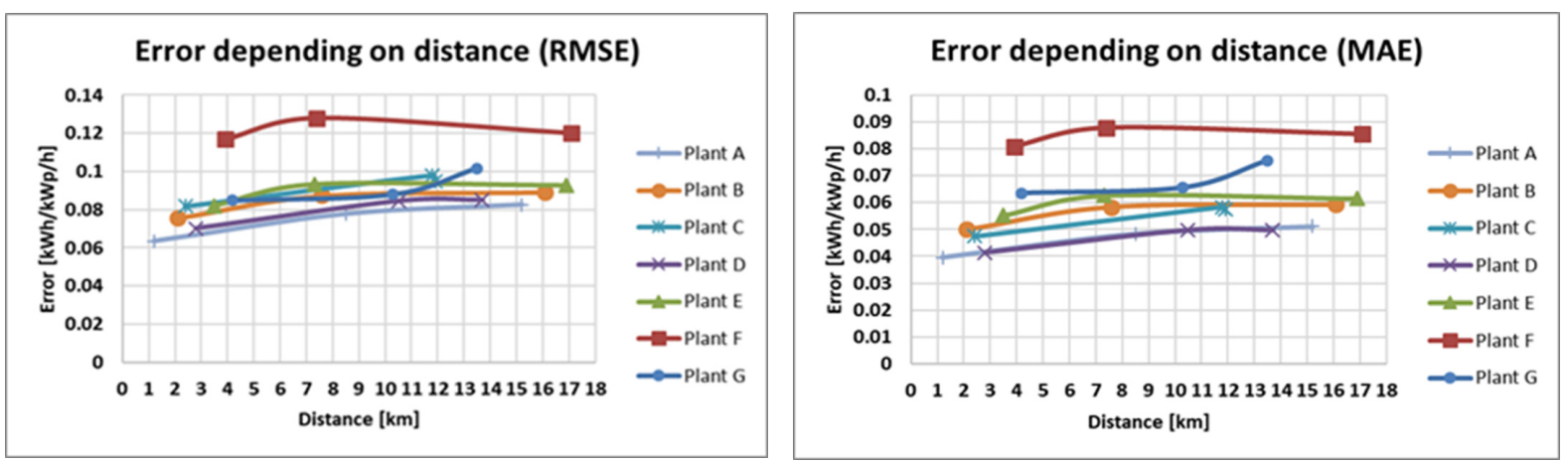

Fig. 4 Variation of error according to distance between input energy and plant 
Therefore, the regression equations were derived to demonstrate that the error increased as the distance increased. To ensure the reliability of the regression equation, $\mathrm{E}$ and $\mathrm{F}$, which are considered abnormal in power generation performance, are excluded. As a result, the following regression equations for the input energy and difference in distance were obtained: $y=0.00136 x+0.07204($ RMSE) and $y=0.0009 x+0.0463$ (MAE).

\section{Analysis of degradation in PV system performance}

Of the seven plants previously examined, we looked at two sites with significant errors between the measured values and the expected values obtained using the proposed performance assessment model. To this end, specific on-site inspections were conducted to analyze the causes of degradation in power generation performance at these sites.

\subsection{Power plant $\mathrm{E}$}

Power plant $\mathrm{E}$ has an installed capacity of $149.94\left[\mathrm{~kW}_{\mathrm{P}}\right]$, a tilt angle of $16\left[^{\circ}\right]$, and an azimuth of $-14\left[^{\circ}\right]$ (SE). Fig. 5 shows the foreground view of plant E, a three-dimensional (3D) model for near shading analysis, and a sun path diagram for far shading analysis. In the plant, lightning rods have been installed at various locations in the areas covered by the PV arrays. In clear climate, direct shading occurs on the modules due to these lightning rods. Thus, during the time of shading, as shown in Fig. 5, the string caused a significant reduction in power generation ${ }^{10,11)}$. In addition, periodic hotspots were generated in the modules, because of which we checked for damage to the bypass diode and degradation of the modules ${ }^{12)}$. As a result, the difference between the measured and expected values was found to be noticeable.

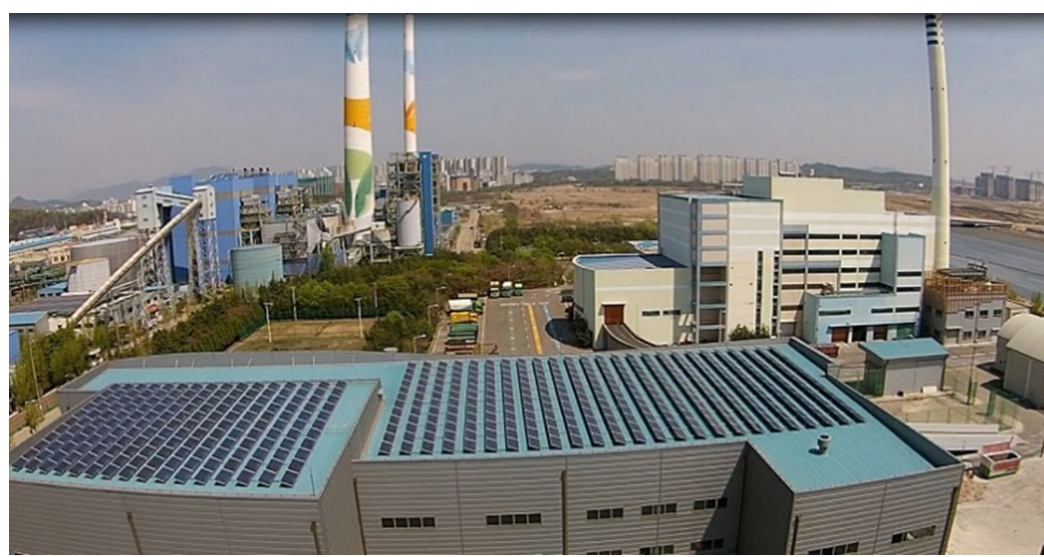

(a) View of power plant E

Fig. 5 On-site inspection for cause analysis of Plant $E$ 

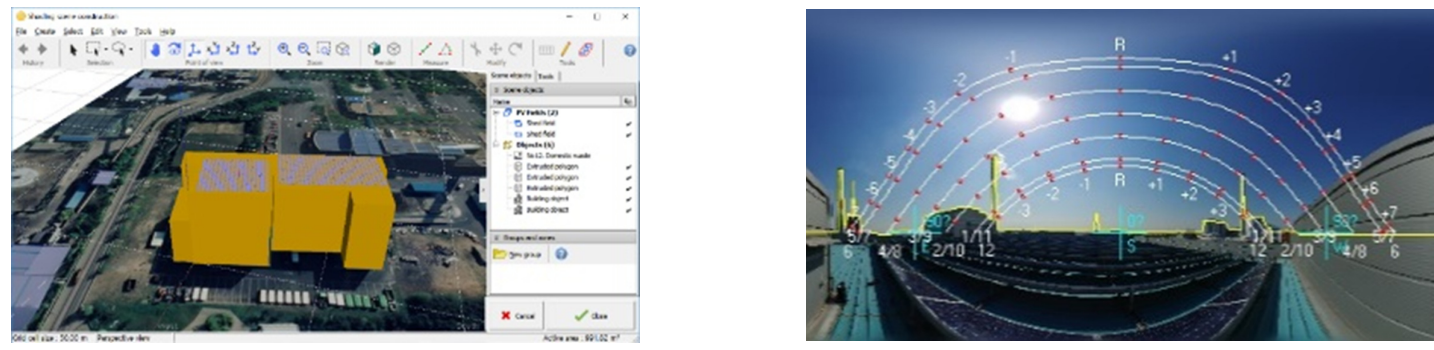

(b) 3D design and sun path diagram

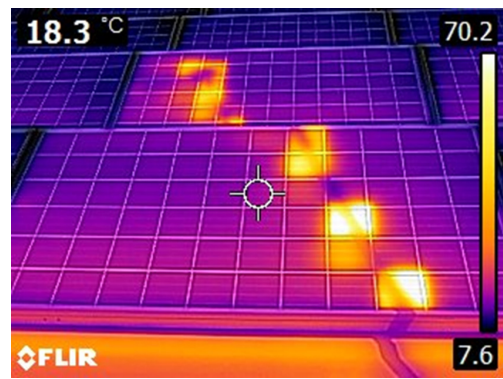

(c) Hotspot by lightning rod

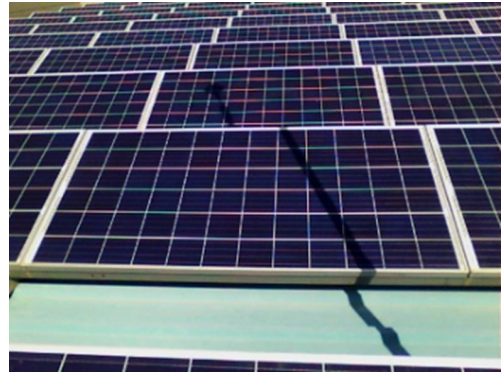

Fig. 5 On-site inspection for cause analysis of Plant $\mathrm{E}$ (Continued)

\subsection{Power plant $\mathrm{F}$}

Power plant $\mathrm{F}$ has an installed capacity of $199.33\left[\mathrm{~kW}_{\mathrm{P}}\right]$, tilt angles of $25\left[^{\circ}\right]$ (attached) and 20, 17, 15, 11, $9,6\left[^{\circ}\right]$ (rounded), and an azimuth of $4\left[^{\circ}\right]$. Seven modules with various tilt angles are installed in the round and attached configurations, and modules with various tilt angles comprise the array, resulting in mismatch losses between modules ${ }^{13)}$. In addition, for the modules installed in the round configuration, the gap between the rear of the module and the roof is narrow, which prevents ventilation ${ }^{14)}$.

Fig. 6 shows an overview of plant F, 3D model for near shading analysis, and a sun path diagram for far shading analysis. In the plant, the PV array located in the rear is heavily shadowed by the array located in the front because the module with the tilt angle of $25\left[^{\circ}\right]$ facing south on the inclined roof (north) has been installed without considering the distance between the arrays. In addition, at low tilt angles, the soling phenomenon was noticeable, and hotspots were caused by soling ${ }^{15)}$. This building was originally constructed as a gymnasium, so large ventilators have been installed around the array. Shading due to the ventilators reduced power generation and caused failure of a bypass diode. In addition to these design-related reasons, differences between the measured and expected values can be ascribed to environmental reasons. 


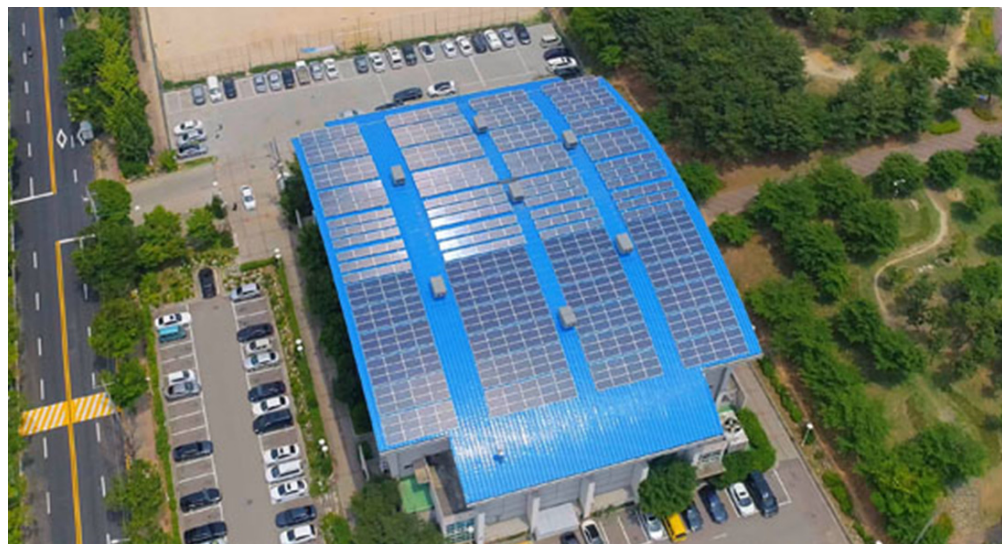

(a) View of power plant $\mathrm{F}$
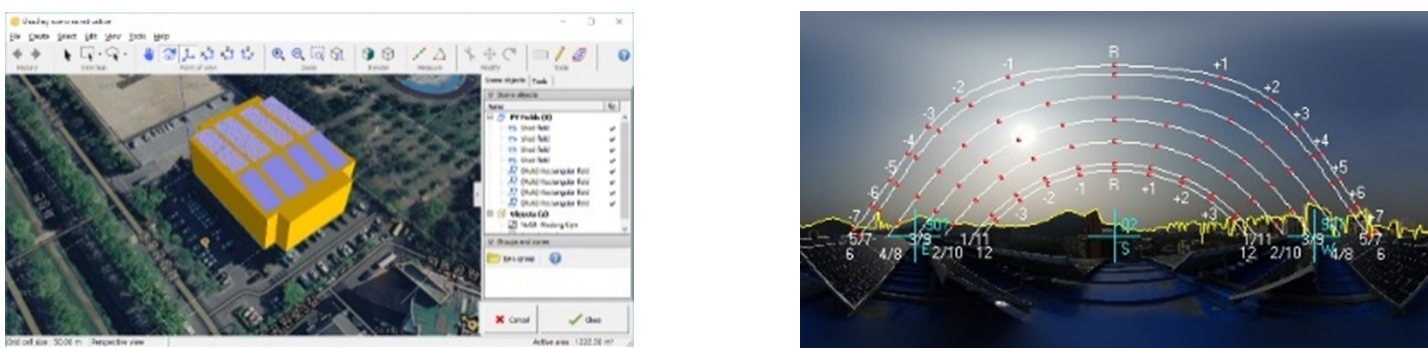

(b) 3D design and sun path diagram

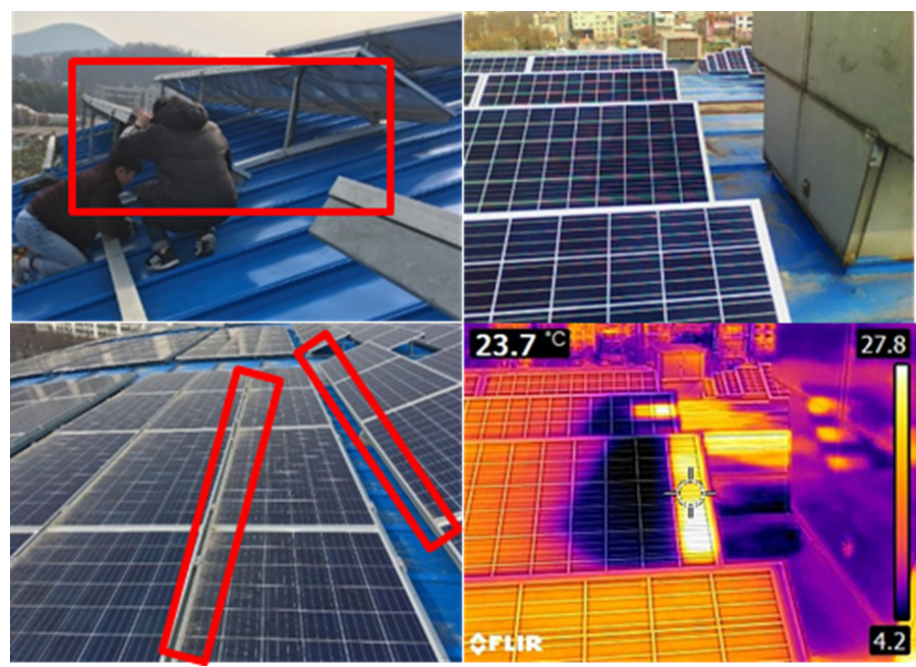

(c) Shading and soiling effects

Fig. 6 On-site inspection for cause analysis of Plant $\mathrm{F}$ (Continued)

\section{Conclusions}

In this study, two results were obtained by evaluating the performance of PV power plants with respect to differences in their distances from the source of input energy.

Cases of the comparison according to the distance between a power plant and the source of input energy 
was classified into 21 based on the three input energy locations. Based on that, it was confirmed using the regression equation that the greater the distance between a power plant and the location of observing the input energy, the error becomes larger. Based on this analysis of the results, the power plants that exhibited deterioration in power generation by themselves were excluded from the comparison to facilitate identification of the causes of deterioration in power generation through on-site analysis by using the proposed performance evaluation model.

In the case of power plant $\mathrm{E}$, a lightning rod installed nearby the array have been reducing the amount of power generation by means of shadings and making the bypass diode hardening so that module degradation caused by periodic hotspots. In the case of power plant F, because the height of each PV array installed on the tilted roof was different, the shading effect of the rear array on the front array adversely affected power generation to a large extent. In addition, the surface temperatures of the PV modules were different from each other according to the two installation types (attached type and inclined type), and it was confirmed that PV modules with different inclination angles were connected to one string. The soil-stacking phenomenon was observed for the PV modules installed with low inclination angles, and hotspots due to soiling were checked. Owing to the characteristics of this building, a large fan was installed on the roof, and the shade generated adjacent to or behind the fan reduced power generation.

Through this study, it was possible to ensure the reliability of performance evaluation, even when the source of input energy was far away from the PV power plant. In addition, by analyzing failure cases in the field (that is, at actual PV power plants), we were able to predict and mitigate potential causes of system failure in advance and, thus, help maintain the power generation performance at the optimal level.

As a future plan, we will verify the reliability at a certain distance in the radial and linear directions between the input energy source and the power plant, and it will contribute to the basic research on the performance evaluation of photovoltaic systems.

\section{ACKNOWLEDGEMENT}

This work was supported by "Human Resources Program in Energy Technology" and "Energy R\&D Program" of the Korea Institute of Energy Technology Evaluation and Planning (KETEP), granted financial resource from the Ministry of Trade, Industry \& Energy, Republic of Korea (No. 20194010000180, 20173030068990). 


\section{REFERENCES}

1. Murdock, H. E., Gibb, D., André, T., Appavou, F., Brown, A., Epp, B., Kondev, B., McCrone, A., Musolino, E., Ranalder, L., Sawin, J. L., Seyboth, K., Skeen, J., and Sverrisson, F., Renewables 2019 Global Status Report, 2019.

2. Murdock, H. E., Adib, R., Lins, C., Guerra, F., Misra, A., Vickery, L., Collier, U., Le Feuvre, P., Bianco, E., Mueller, S., Philibert, C., Schmidt, O., Kvarnstroem, O., Hungerford, Z., Frankl, P., Hawila, D., Ferroukhi, R., Renner, M., Nagpal, D., Cox, S., Esterly, S., Preiesmann, C., Taylor, H., Breitschopf, B., and Van Rooijen, S., Renewable Energy Policies in a Time of Transition, 2018.

3. IRENA, Future of Solar Photovoltaic: Deployment, Investment, Technology, Grid Integration and SocioEconomic Aspects (A Global Energy Transformation: Paper), International Renewable Energy Agency, 2019.

4. Lee, K. S., PV power plant design considerations of IECRE OD-403, Global Photovoltaic Conference 2017, 2017.

5. Kwon, O. H. and Lee, K. S., Suggestion of PV System Performance Assessment Method Using Meteorological Monitoring System and Performance Evaluation Model, 2019 IEEE $46^{\text {th }}$ Photovoltaic Specialists Conference (PVSC), pp. 1264-1269, 2019.

6. Sukumaran, S. and Sudhakar, K., Fully Solar Powered Raja BHOJ International Airport: A Feasibility Study, Resource-Efficient Technologies, Vol. 3, No. 3, pp. 309-316, 2017.

7. Mahachi, T., and Rix, A., PVsyst Model Improvement using Field Data From a 75 MWp Solar PV Power Plant in South Africa, Proc. 24th SAUPEC, Vol. 2B-1, 2016.

8. Apostolou, G., Reinders, A., and Verwaal, M., Comparison of the Indoor Performance of 12 Commercial PV Products by a Simple Model, Energy Science \& Engineering, Vol. 4, No. 1, pp. 69-85, 2016.

9. Willmott, C. J. and Matsuura, K., Advantages of the Mean Absolute Error (MAE) Over the Root Mean Square Error (RMSE) in Assessing Average Model Performance, Climate Research, Vol. 30, pp. 79-82, 2005.

10. Del Buono, M., Armani, M., Pötz, B., Cattani, D., and Sparber, W., Performance Measurements and Monitoring of Shadow Effects on PV Systems, In 23rd European Solar Energy Conference and Exhibition Valencia, Spain, 2008.

11. Manduch, V., Navrh Ochrany FVE Pri Uderech Blesku a Jisteni Datovych Rozvodu. Diploma Thesis, Brno: Brno University of Technology, 2012.

12. Ko, S. W., Ju, Y. C., Hwang, H. M., So, J. H., Jung, Y. S., Song, H. J., Song, H. E., Kim, S. H., and Kang, G. H., Electric and thermal Characteristics of Photovoltaic Modules Under Partial Shading and with a Damaged Bypass Diode, Energy, Vol. 128, pp. 232-243, 2017.

13. Massi Pavan, A., Mellit, A., De Pieri, D., and Lughi, V., A Study on the Mismatch Effect Due to the Use of Different Photovoltaic Modules Classes in Large-Scale Solar Parks, Progress in Photovoltaics: Research and Applications, Vol. 22, No. 3, pp. 332-345, 2014.

14. Ritzen, M. J., Vroon, Z. A. E. P., Rovers, R., and Geurts, C. P. W., Comparative Performance Assessment of a Non-Ventilated and Ventilated BIPV Rooftop Configurations in the Netherlands, Solar Energy, Vol. 146, pp. 389-400, 2017.

15. Cano, J., Photovoltaic Modules: Effect of tilt angle on soiling, Arizona State University, pp. 34-47, 2011. 